between these is far greater than can be put down to experimental error. The former kind occurs also in the fatty acid chains, where each carbon also has four neighbours, two carbons and two hydrogens. The latter is found in anthracene and naphthalene, the basis of these substances being the benzene ring: in these the carbon has three neighbours as in graphite. It may prove to be the case that the former kind of bond is peculiar to the aromatic substances and the latter to the aliphatic. The heats of combustion of diamond and graphite are very nearly the same: so that it takes as much energy to break down the four bonds in the diamond as the three in the graphite. In such a comparison the heat spent on breaking the weak bonds between the network layers of graphite is taken to be negligible.

Such accurate measurements as these encourage the hope that there are exact rules as to distances apart of the atoms, and very probably as to their mutual orientation. Knowledge of these rules will greatly facilitate the determination of structure.

What has been said above may serve to show how cagerly the new powers of detecting mole. cular arrangement in the solid are being used. With the knowledge gained in this way we may learn more of the forces which bind all atoms and molecules together, and in particular consolidate and give form and function to the various constituents of the living body.

\title{
Biometric Studies of Twins
}

A MEMOIR with the title "A 13iometric A Investigation of Twins and their Brothers and Sisters", by Dr. Percy Stocks assisted by Mary N. Karn, printed in the Annals of Eugenics (vol. 5, Jan. 1933), forms part 2 of a paper of which part 1 was published in the same Annals in 1930 and was noticed in Nature of November 15, 1930 (vol. 126, p. 766).

Part 1 dealt with the characters, height, weight, head length, head breadth, head circumference, interpupillary distance, blood pressure, pulse and respiration rates, colour of eyes and hair, degree of facial resemblance and finger prints. In the present part, the measurements of strength of grip, acuity of vision, colour vision, cutaneous sensibility and upper limit of auditory sensibility are analysed by the same technique, the mental measurements are discussed, and two special problems are also dealt with: (1) asymmetry in relation to twinning, (2) correlation between physical measurements in the same individual, and the question whether this is any different in monozygotic twins from the value found for other children. For the methods of distinguishing monozygotic twins from dizygotic twins, when the twins are of the sane sex, reference must be made to the previous memoir: the decision is made partly on the basis of finger prints and partly on the basis of physical characters.

Monozygotic twins were found to have a stronger mean hand grip than other children of the same ages, as might be expected from their superior height. For dizygotic and monozygotic twins respectively the correlations between members of the pair, corrected for experimental errors and day to day fluctuations, were found to be of the order 0.4 and $0 \cdot 7$. The former implies resemblance to the same degree as for ordinary siblings, and the power to grip seems to be relatively dependent on inherited constitution and environmental influences in about the same proportions as in the case of blood pressure, pulse and respiration. For visual acuity, cutaneous sensibility and sensitive- ness to sounds of high frequency, dizygotic twins again resemble each other to the same degree as ordinary siblings, the coefficients being of the order $0 \cdot 25-0 \cdot 3$. For visual acuity the coefficient for monozygotic twins is higher, about 0.5 ; but for the other sensory tests this result is more doubtful. It is clear, however, that heredity plays some part in the development of these characters. No evidence was found for an increased tendency to symmetry-reversal in monozygotic twins, when tested either by strength of grip of the right and left hands or by acuity of vision for the right and left eyes.

The results of the mental tests are of special interest, as they have an emphatic bearing on the interpretation of these tests. The coefficients of correlation between members of the pair are about 0.85 for monozygotic twins, 0.65 or more for dizygotic twins of the same sex, and about 0.15 for siblings. As the authors state, it is difficult to account for the high degree of resemblance in dizygotic like-sexed pairs without admitting that the close association of one twin with another plays an important part in producing like responses to these tests: the responses appear to be a measure, not as is often assumed of virgin intelligence, but of intelligence and the effect of experience superposed.

Height is more highly correlated with weight and with head dimensions in monozygotic twins than in others, though for most characters there is no regular or significant difference. The authors argue that, if monozygotic twins arise by the primary division of a single fertilised ovum, it might be expected that, unless the primary division of every component of the cell occurred with exactness, there could result a lower correlation between different characters in the same individual amongst monozygotic twins than amongst the other types. But is this conclusion necessary? If two characters are determined by $a+b$ genes and $b+c$ genes respectively, the $b$ genes being common to the two, the genetic correlation is dependent 
solely on the proportion $b / \sqrt{ }(a+b) \cdot(b+c)$, and there seems no reason why this proportion should tend to be lowered by chance fluctuations in the cell-division.
The memoir concludes with twelve pages of tables containing all the measurements taken, and the two parts together should form a classic in the growing literature of the subject.

\section{Obituary}

\section{DR. Sydney A. KAY}

$\mathrm{S}^{\mathrm{Y}}$ YDNEY ALEXANDER KAY was born in Dundee in 1874 and after leaving the High School became a student at University College, Dundee, under Prof. (now Sir) James Walker. The association thus begun continued through most of Kay's life. His student career was a brilliant one - he gained the medals in chemistry, natural philosophy, mathematics and physiology. Graduating as B.Sc. in 1896, he engaged in research with Walker, and two papers-"On the so-called Magnesium Hypoiodite" (Proc. Roy. Soc. Edin., 21,236 ; 1896) and "Velocity of Urea Formation in Aqueous Alcohol"' (J. Chem. Soc., 71, 489 ; 1897)-recorded the investigations. The award of an 1851 Fxhibition scholarship enabled him to study under Arrhenius at Stockholm and under Ostwald at Leipzig. The work done at Stockholm furnished material for a lengthy paper on "Equilibrium between Sulphuric Acid and Sulphates in Aqueous Solution" (Proc. Roy. Soc. Edin., 22, 484 ; 1899).

The next ten years were spent at St. Andrews, where Kay proved himself a most efficient assistant to Prof. Purdie and an extraordinarily conscientious teacher. Perhaps one might say that conscientiousness was his outstanding quality. While at St. Andrews the degree of D.Sc. was conferred upon him in 1902, and three years later he became a fellow of the Chemical Society, London.

On the retirement of Prof. Purdie in 1909, Kay transferred to Edinburgh; once more to be associated with Walker, who had succeeded Crum Brown in the chair of chemistry in the previous year. He devoted himself anew to teaching and more especially the teaching of chemical analysis. The textbook-Cumming and Kay's "Quantitative Chemical Analysis"-first appeared in 1913, the fifth edition in 1928 and, at the time of his death, Kay was looking forward to a term's leave of absence to be occupied in bringing out a completely revised edition of the book. Another volume by Kay alone appeared in 1921 under the title "Qualitative Analysis of Inorganic Substances". He became much interested in water analysis and with Walker published "The Acidity and Alkalinity of Natural Waters" (J. Soc. Chem. Ind., 31, 1013; 1912) and with Susan H. Newlands "Determination of the Hardness of Natural Waters and the Use of Methyl Red as an Indicator" and "The Determination of Calcium and Magnesium in Natural Waters" ( $J$. Soc. Chem. Ind., 35, 445 and $447 ;$ 1916). During the second half of the War he did good service as deputy inspector of high explosives for the south of Scotland.
Kay was appointed a lecturer in chemistry in 1914 and from 1922 gave lectures to the agriculture and forestry students and was in charge of the Advanced Inorganic Laboratory. From him, many students learned method and accuracy and the value of skilful manipulation.

Kay was a lover of Nature and his vacations were generally spent in the Highlands, where he found great happiness in the study of wild life. His skill with the camera was notable and he was at one period presiclent of the St. Andrews Amateur Photographic Society. In 1905 he married Margaret Frazer Plenderleath. The union proved a happy one and the sympathy of his colleagues and friends goes out to her in her great beroavement. After a very brief illness Dr. Kay died on May 26, and those of us who knew him have lost a true friend.

$$
\text { J. F. M. }
$$

\section{Dr. Norman U. MkLdrum}

THE death of Dr. Norman Urquhart Meldrum on June 7, at the early age of twenty-five years, has robbed biochemistry of an exceptionally active and brilliant young worker. A month earlier he had had a riding accident, from the effects of which he had not fully recovered. He was educated at the University of Edinburgh, where he took his B.Sc. degree in 1928 . In the same year he became a member of Emmanuel College, Cambridge, and joined the Biochemical Laboratory with a grant from the Carnegie Fund. In 1930 he obtained a Beit fellowship (for medical research) which he held until his death. He took the Cambridge Ph.D. in 1931 .

Immediately after the isolation of crystalline tripeptide glutathione by Hopkins in 1929, Meldrum and Dixon investigated its properties, and found that these differed unexpectedly from those of Hopkins's amorphous preparation of 1921. Until his death Meldrum continued working on the properties and functions of glutathione in the organism, but published no other large papers on the subject. He also gave some attention to other problems such as the denaturation of proteins.

After taking his doctor's degree, Meldrum joined Roughton in his investigation of the carbon dioxide catalyst present in blood. This co-operation speedily led to the isolation of a new enzyme, carbonic anhydrase, the study of which has opened up a large new field of work (see NaTURE of June 17, p. 874). Meldrum's biochemical knowledge was of the greatest value in this research.

Meldrum had a real genius for getting to the heart of a biochemical problem and it was this, 